\title{
The critically endangered Asiatic cheetah Acinonyx jubatus venaticus in Iran: a review of recent distribution, and conservation status
}

\author{
Mohammad S. Farhadinia ${ }^{1,2}$ (ID) Luke T. B. Hunter ${ }^{3}$. \\ Alireza Jourabchian $^{4}$ - Fatemeh Hosseini-Zavarei ${ }^{1}$ • \\ Hasan Akbari $^{5} \cdot$ Hooshang Ziaie $^{6}$ - George B. Schaller ${ }^{3,7}$. \\ Houman Jowkar ${ }^{8,9}$
}

Received: 9 September 2016/Revised: 5 January 2017/Accepted: 20 January 2017/ Published online: 3 February 2017

(C) The Author(s) 2017. This article is published with open access at Springerlink.com

\begin{abstract}
Considerable effort has been put into conservation of the critically endangered Asiatic cheetah Acinonyx jubatus venaticus in Iran during the past few decades, and a thorough review of the species' status, demography, range and conservation is provided here. We collated a large dataset of all verified occurrence data, photographic records and mortality cases since 1980 throughout the species' range in Iran. Currently, the cheetah is
\end{abstract}

Communicated by Karen E. Hodges.

Electronic supplementary material The online version of this article (doi:10.1007/s10531-017-1298-8) contains supplementary material, which is available to authorized users.

Mohammad S. Farhadinia

mohammad.farhadinia@zoo.ox.ac.uk

Luke T. B. Hunter

lhunter@panthera.org

Alireza Jourabchian

ali_jourabchian@yahoo.com

Fatemeh Hosseini-Zavarei

fhosseini806@gmail.com

Hasan Akbari

haenv@yahoo.com

Hooshang Ziaie

ziaie_h@yahoo.com

George B. Schaller

gbs.kms@gmail.com

Houman Jowkar

h.jowkar@gmail.com

1 Project Future4Leopards, Tehran, Iran

2 Wildlife Conservation Research Unit, Department of Zoology, University of Oxford, Recanti-

Kaplan Centre, Tubney House, Oxford, Oxfordshire OX13 5QL, UK 
distributed throughout the arid landscapes of the eastern half of Iran, but the limits of its current and past range as well as population trends are uncertain. Surveys of nearly 40 different areas resulted in 18 localities with confirmed presence of cheetahs in recent years. Camera trapping has been an effective tool to provide evidence of presence and status of cheetahs, revealing the species' extremely low density and long inter-reserve movements. Together with photographic records, a total of 82 different cheetahs were detected during the 2000s in Iran. Protection status in most areas has been elevated by the Iran government. Asiatic cheetahs are highly vulnerable to extinction, mainly due to causalities mediated by herder persecution, poaching and road collisions as well as prey and habitat loss. Some efforts have been made to address these threats, but range expansion in recent years is a result of greater survey effort, rather than population recovery. We suggest that, despite conservation investment of the last 15 years, the species remains critically endangered on the verge of extinction.

Keywords Arid landscapes · Asiatic cheetah - Camera trap · Extent of occurrence · Iran

\section{Introduction}

The cheetah (Acinonyx jubatus) once had a distribution that extended across the Middle East, Central Asia into southern Kazakhstan and across India almost to the border with Bangladesh (Caro 1994). Today outside of Africa, the cheetah has been extirpated from its entire Asiatic range except for a small population in the Islamic Republic of Iran (Farhadinia 2004). Occasional reports of cheetahs arise from neighboring countries but with the exception of skins likely in trade, there has been no physical evidence of the species outside Iran since 1982 (Pakistan: Roberts 1997; Husain 2001; Afghanistan: Manati and Nogge 2008; Turkmenistan: Jackson 1998).

Historically, the cheetah in Asia has been classified with North African cheetahs as a discrete subspecies, A. j. venaticus (Pocock 1939; Ellerman and Morrison-Scott 1966). Morphological differences between African and Asiatic cheetahs are slight, with various authors (Dareshuri 1978; Karami 1992) attempting to delineate differences in morphology and pelage with equivocal results. However, recent analysis of a large sample of archaeozoological and contemporary samples demonstrated that Asiatic cheetahs (i.e., A. $j$. venaticus) are unambiguously separated from African subspecies, with a putative split between Asiatic and African populations at 32,000-67,000 years ago (Charruau et al. 2011).

\footnotetext{
3 Panthera, 8 West 40th Street, 18th Floor, New York, USA

4 Tehran, Iran

5 Iran Department of Environment (DoE), Yazd Provincial Office, Yazd, Iran

6 Islamic Azad University, North Tehran Branch, Tehran, Iran

7 Wildlife Conservation Society, 2300 Southern Blvd, Bronx, NY 10460, USA

8 Conservation of Asiatic Cheetah Project, Iran Department of Environment, Tehran, Iran

9 Persian Wildlife Heritage Foundation, Tehran 15856-86341, Iran
} 
The cheetah is globally considered as Vulnerable (but see Durant et al. (2016) for a rationale to up-list the species to 'Endangered'), whereas the Asiatic cheetah is categorized as Critically Endangered on the IUCN Red List (Durant et al. 2015). In Iran, the subspecies has become the most prominent symbol of the country's imperiled wildlife and conservation efforts (Hunter et al. 2007; Jourabchian and Farhadinia 2008). With the future of the cheetah so precarious, Iran's Department of the Environment (DoE) launched a major initiative entitled "Conservation of the Asiatic Cheetah, Its Natural Habitat, and Associated Biota in the I.R. of Iran" (CACP) in 2001 to mitigate threats to cheetahs, their prey and their habitats (Hunter et al. 2007; Breitenmoser et al. 2009).

Additionally, the CACP and associated NGOs started conducting ongoing surveys to determine the distribution and abundance of cheetahs, other large carnivores and ungulates. This paper summarizes the results of those survey efforts and provides all known records of the Asiatic cheetah since 2001. We place the present status of the Asiatic cheetah in context with a comparison to all known records from 1980 to the inception of the CACP. Finally, we summarize the present threats and conservation status of the cheetah in Iran, and provide recommendations for urgent conservation activities.

\section{Methods}

We compiled all known records of Asiatic cheetahs in Iran between 1980 and 2012. We established a database hosting data from various sources which were grouped into two main periods; before 2001 (in which no concerted conservation effort was made), and after 2001 when a comprehensive conservation program to save the cheetah was implemented in Iran. We created the historic range (up to c. 1980) of the cheetah in Iran based on available resources (Dareshuri and Harrington 1976; Asadi 1997; Ziaie 2008; Jourabchian and Farhadinia 2008).

\section{Pre-2001 records}

We collected pre-2001 records of cheetah presence from grey literature, including DoE newsletters, mission reports, nature magazines, university dissertations and books (in total ca. 470 sources). We only used documents produced by trained biologists, such as DoE experts, chief game guards or university students and excluded all sources which we were unable to prove their reliability, based on authors' experience. Additionally, we visited 42 museums and public collections in Iran to examine preserved specimens. Finally, we contacted foreign museums $(\mathrm{n}=10)$ perceived to store samples from Iranian cheetahs.

\section{Direct sighting}

We interviewed ca. 335 protected area personnel, hunters, researchers, taxidermists, and collectors within the species' historic range in Iran. Since the majority of cheetah habitat in Iran hosts very few people for most of the year, our interview efforts focused chiefly on protected area personnel. We also interviewed local people where there was unambiguous physical evidence they had seen a cheetah, such as photographs, clear tracks, or killed livestock. Tracks were accepted as evidence of presence if they were indicated to one of us. For each direct sighting, date, time, GPS location, and age/sex composition were recorded. 
If the presence of cubs was unequivocal, we recorded the adult as a female. All other sightings where the sex could not be determined were recorded as unknown.

Families (female with dependent cubs) were recorded as evidence of reproduction. These records were based on physical evidence examined by at least one of the authors (i.e., 'confirmed') or sightings by experienced game guards (considered here as 'suspected'). Cheetahs accompany their cubs on average 17 months (Caro 1994) and are known to cover multiple adjacent reserves (Farhadinia et al. 2013, 2016a). In order to avoid double counting, we were conservative in estimating the number of unique families. We regarded all records of a female with cubs within a 17-month period from the same area as a single family.

\section{Cheetah mortality}

We recorded all cheetah mortalities reported to us by hunters, game guards and cases reported to DoE. We considered a report as credible when there was supporting physical evidence or confirmation from a secondary source, such as trained game guards or experts. Where possible, we recorded the cause of mortality, which was unequivocal in all cases where people were the agents. Where cheetahs were found dead (usually by game guards) in the field with no evidence of human agency, we classified cases as 'suspected natural causes'.

\section{Camera trapping and other photographic records}

Unlike many habituated cheetah populations in Africa, Asiatic cheetahs are extremely shy and also live at very low densities, which pose a challenge for surveys in Iran (Hunter et al. 2007). Direct observations are rare and fleeting, so we also conducted cheetah surveys using passive infrared camera traps. Camera-traps are not manufactured in Iran, and their availability has been constrained by economic sanctions and high import costs. Accordingly, our effort focused on securing evidence of cheetah presence from as large a survey areas as possible, rather than adhering to formal mark-recapture design (Karanth and Nichols 2002). Where possible, we designed surveys incorporating mark-recapture principles, for example, when a large number of cameras were available to deploy at a single site.

Given the limited availability of equipment in Iran, a variety of brands were used, mainly from CamTrak (CamTrak South Inc., Watkinsville, Georgia, USA) between 2001 and 2006, later supplemented with cameras made by Panthera (New York, NY 10018, USA), DeerCam (DC-200 model, Park Falls, WI) and Cuddeback Capture (Green Bay, WI, USA). In each intensive survey, between 10 and 50 cameras were used for 30 to 120 days (Supplemental Material Table 1). Cameras were placed in key features of the landscape preferred by cheetahs, such as game trails, dried watercourses, 'playtrees' (i.e., isolated or prominent trees that cheetahs regularly visit for scent marking), natural springs or artificial water sources. We also provided cameras to protected areas' personnel and trained them in their use to deploy opportunistically at promising locations, for example, following recent sightings of cheetahs or when fresh tracks were located, generating secondary sources of camera trap data, i.e., targeted camera trapping. Furthermore, we compiled all available photographs taken by game guards or visitors. We included images from both kinds of camera trapping effort (i.e., intensive surveys and targeted) as well as all opportunistic photos in a single database. An interval of one hour between camera trap images was used to recognize independent capture events. 
Individuals that were photographed post-2001 (and the onset of camera-trapping) were identified by discriminating unique spot patterns. Where possible, photo-trapped adult cheetahs were sexed by testes or dependent cubs. Age categorization was modified from Marker and Dickman (2003) in four age groups: (1) Cubs (0-12 months); (2) Adolescents (>12 months to 18 months, still dependent on mother); (3) Sub-adults, or newly independent cheetahs ( $>18$ months to 30 months), identified by presence of long dorsal hair as a mane on their nape (Caro 1994); and (4) Adults (>30 months).

The CACP effort was initially focused on five priority areas where cheetahs were known to exist prior to 2001, namely Naybandan Wildlife Refuge (WR), Touran Biosphere Reserve (BR), Kavir National Park (NP), Bafq Protected Area (PA) and Dareh Anjir WR (Jourabchian 1999; Ziaie 2008). Accordingly, camera traps were initially deployed only within these areas to generate data on the extent of range and minimum numbers there. As reports or evidence of the species emerged from other sites and more camera-traps were acquired, the survey effort was expanded (Supplemental Material Table 2).

\section{Extent of occurrence}

Using occurrence data, we calculated "Extent of Occurrence (EOO)" for cheetahs. According to IUCN (2001), EOO is defined as "the area contained within the shortest continuous imaginary boundary which can be drawn to encompass all the known, inferred or projected sites of present occurrence of a taxon, excluding cases of vagrancy. This measure may exclude discontinuities or disjunctions within the overall distributions of taxa (e.g., large areas of obviously unsuitable habitat). EOO can often be measured by a minimum convex polygon." The Asiatic cheetah shows long inter-reserve movements in Iran (Farhadinia et al. 2013, 2016a) and we believe that the calculated EOO can provide a reasonable estimate of the range loss trends in the country.

\section{Results}

\section{Demography}

1980-2001 produced 382 cheetah sightings (not 382 unique individuals) on 180 occasions. $1-7$ cheetahs were seen per sighting (mean group size $=2.1$, SE 0.1 ) with nearly half $(48.3 \%)$ of records made up by sightings of solitary individuals.

2001-2012 yielded 873 records of cheetahs on 461 occasions. Except for an exceptionally large group of ten individuals seen in November 2007 in Ariz No Hunting Area (NHA), 1-6 cheetahs were seen at a time (mean group size $=1.9$, SE 0.6), with solitary sightings comprising more than half of the reports $(53.6 \%)$.

A total of 49827 trap nights of camera-trapping effort produced 283 independent photographs of 49 different cheetahs, 17 males, 10 females and 22 of unknown sex between 2001 and 2012 (Supplemental Material Table 1). Opportunistic, targeted camera trapping (49 independent events; Supplemental Material Table 3), identified 27 cheetah individuals, 9 of which were also photographed during systematic surveys. Accordingly, targeted efforts to utilize limited number of camera traps helped to recognize 18 cheetahs which were not recorded during surveys. Together with individuals identified from photographs taken by game guards and visitors ( 15 cheetah individuals), a total of 82 different individuals were recorded between 2001 and 2012 in Iran. Overall, a balanced sex ratio 
(20:20) occurred among sexed cheetah individuals (Table 1). Only six cheetah individuals were present in pictures for more than three years ( 5 males, 1 female). $73.2 \%(n=60)$ cheetahs were recognized based on camera trap images whereas $36.6 \%(n=30)$ were obtained by handheld cameras (eight individuals were photographed both ways)

Post-2001, 32 different litters were recorded from 10 sites, of which 17 (53.1\%) were confirmed by images. Touran BR produced the largest number of records of breeding with at least 9 different families $(28.1 \%)$. We failed to obtain evidence of cheetahs breeding in 8 sites (Table 1). 75 cheetah cubs were individually identified since $2001,56.0 \%(\mathrm{n}=42)$

Table 1 Details of the individual cheetahs confirmed in different areas of Iran between 2001 and 2012

\begin{tabular}{|c|c|c|c|c|c|c|}
\hline No. & Site & Province & $\begin{array}{l}\text { No. cheetah } \\
\text { photographed }\end{array}$ & No. cheetah deaths ${ }^{\mathrm{a}}$ & $\begin{array}{l}\text { No } \\
\text { cheetah } \\
\text { families } \\
\text { confirmed }^{\mathrm{b}}\end{array}$ & $\begin{array}{l}\text { No } \\
\text { cheetah } \\
\text { families } \\
\text { suspected }^{\mathrm{c}}\end{array}$ \\
\hline 1 & Touran & Semnan & $13(5 \mathrm{M}, 5 \mathrm{~F}, 3 \mathrm{U})$ & $7(2 \mathrm{M}, 3 \mathrm{~F}, 2 \mathrm{C})$ & 6 & 3 \\
\hline 2 & Kavir & Semnan & $2(1 \mathrm{M}, 1 \mathrm{U})$ & $6(6 \mathrm{U})^{\mathrm{d}}$ & 0 & 1 \\
\hline 3 & $\begin{array}{l}\text { Khosh } \\
\text { Yeilagh }\end{array}$ & Semnan & $1(1 \mathrm{U})$ & $1(1 \mathrm{U})$ & 0 & 0 \\
\hline 4 & Naybandan & $\begin{array}{l}\text { South } \\
\text { Khorasan }\end{array}$ & $\begin{array}{c}19(3 \mathrm{M}, 3 \mathrm{~F}, \\
13 \mathrm{U})\end{array}$ & $2(1 \mathrm{M}$ and $1 \mathrm{U})$ & 1 & 3 \\
\hline 5 & Bafq & Yazd & $10(3 \mathrm{M}, 3 \mathrm{~F}, 4 \mathrm{U})$ & $5(1 \mathrm{M}, 1 \mathrm{~F}, 3 \mathrm{C})$ & 2 & 1 \\
\hline 6 & Dareh Anjir & Yazd & $\begin{array}{l}20(5 \mathrm{M}, 4 \mathrm{~F} \\
11 \mathrm{U})\end{array}$ & $3(2 \mathrm{M}, 1 \mathrm{U})$ & 4 & 1 \\
\hline 7 & Siahkouh & Yazd & $4(3 \mathrm{M}, 1 \mathrm{~F})$ & 0 & 1 & 1 \\
\hline 8 & Ariz & Yazd & $1(1 \mathrm{~F})$ & 0 & 0 & 0 \\
\hline 9 & Kalmand & Yazd & 0 & $6(3 \mathrm{M}, 2 \mathrm{~F}, 1 \mathrm{U})$ & 0 & 2 \\
\hline 10 & $\begin{array}{l}\text { Kamki } \\
\text { Bahabad }\end{array}$ & Yazd & 0 & $1(1 \mathrm{U})$ & 0 & 0 \\
\hline 11 & Abbas Abad & Esfahan & $1(1 \mathrm{U})$ & 0 & 0 & 1 \\
\hline 12 & Darband & Kerman & $1(1 \mathrm{U})$ & $7(3 \mathrm{M}, 1 \mathrm{~F}, 3 \mathrm{C})$ & 0 & 1 \\
\hline 13 & Dorouneh & $\begin{array}{l}\text { Razavi } \\
\text { Khorasan }\end{array}$ & $1(1 \mathrm{~F})$ & 0 & 0 & 0 \\
\hline 14 & Miandasht & $\begin{array}{l}\text { North } \\
\text { Khorasan }\end{array}$ & $7(2 \mathrm{M}, 3 \mathrm{~F}, 2 \mathrm{U})$ & 0 & 3 & 3 \\
\hline 15 & Chah Shirin & Semnan & $1(1 \mathrm{U})$ & $1(1 \mathrm{~F})$ & 0 & 0 \\
\hline 16 & Boshrouyeh & $\begin{array}{l}\text { North } \\
\text { Khorasan }\end{array}$ & 0 & $1(1 \mathrm{U})$ & 0 & 0 \\
\hline 17 & Rafsanjan & Kerman & 0 & 0 & 0 & 0 \\
\hline \multirow[t]{2}{*}{18} & Takhti Iran & $\begin{array}{l}\text { Norkh } \\
\text { Khorasan }\end{array}$ & 0 & 0 & 0 & 0 \\
\hline & Total & & $\begin{array}{l}82(20 \mathrm{M}, 20 \mathrm{~F}, \\
42 \mathrm{U})\end{array}$ & $\begin{array}{l}40(12 \mathrm{M}, 8 \mathrm{~F}, 8 \mathrm{C}, \\
12 \mathrm{U})\end{array}$ & 17 & 15 \\
\hline
\end{tabular}

\footnotetext{
${ }^{\text {a }} M$ male, $F$ female, $C$ cub, and $U$ unknown sex/age

b Confirmed families are associated with evidence such as film or photo

c Suspected families are reported by trained game guards and have been sometimes verified in the field based on tracks but lack physical evidence for corroboration (see Methods)

${ }^{\mathrm{d}}$ Four individuals were reportedly killed by herders outside Kavir NP and two individuals were found dead inside the area
} 
confirmed by camera trapping. A further 33 cubs were observed, mainly by park personnel, without corroborating photographs but which were clearly separated by time and distance.

Between 2001 and 2012, 42 different cheetahs were found dead (Table 2). Illegal anthropogenic killing, mainly by herders (and their dogs) or poachers was the greatest cause of death, accounting for 21 individuals (50.0\%), followed by road mortalities which killed 12 cheetahs (28.6\%; ten adults and two cubs), with almost equal sex ratio. Seven cases $(17.5 \%)$ were due to suspected natural causes, including one individual which was killed by other carnivores.

We were able to recognize at least 26 cheetah individuals based on images available of dead cheetahs, only three of which were also recorded during camera-trap surveys. Therefore, the minimum number of individual cheetahs we recorded between 2001 and 2012 is 105 (Tables 1, 2).

\section{Range and distribution}

The cheetah historically occurred widely across the country with an estimated total EOO of $1045,671 \mathrm{~km}^{2}$ or approximately $63.4 \%$ of the country's territory (Fig. 1). Since 2001, the cheetah is known from only the seven predominantly desert provinces of Yazd, Semnan, Esfahan, North Khorasan, Razavi Khorasan, South Khorasan and Kerman with a putative extent of occurrence of approximately $242,500 \mathrm{~km}^{2}$ (Fig. 1), equal to $23.2 \%$ of its historic occurrence.

Between 1980 and 2001, the cheetah was confirmed through documented records from eleven sites, namely Ariz NHA, Bafq PA, Dareh Anjir WR, Dorouneh PA, Kamki Bahabad NHA, Kavir NP, Naybandan WR, and Touran BR (Karami 1992; Asadi 1997; Jourabchian and Farhadinia 2008) as well as Khabr NP, Shahdad and Bahram-e Gour Protected Area (PA) (Jowkar 1999). Between 2001 and 2016, the cheetah was confirmed unequivocally from an additional seven sites (Supplemental Material Table 2). Furthermore, the cheetah's existence was considered as confirmed based on photographs of footprints in three additional areas, namely Rafsanjan County (Kerman Province), Takhti Iran NHA (North Khorasan Province) and Chah Shirin NHA (Semnan Province) during 2000s. No additional evidence is available from these areas and reports may represent transient individuals, but counting all recent records, Asiatic cheetahs have occurred in at least 21 areas since 1980. However, recent surveys in Khabr NP, Shahdad and Bahram-e Gour Protected Area (Ghoddousi et al. 2007; Jourabchian and Farhadinia 2008) have failed to find recent evidence of cheetahs in these areas, bringing the total number of known cheetah areas at the time of writing to 18 in seven provinces (Fig. 1). All sites except Rafsanjan and Boshrouyeh Counties are now officially protected by the Iranian government (see Supplemental Material Table 2).

The following section summarises all records of cheetahs by region.

\section{Southern Alborz region (Tehran and Semnan Provinces)}

The cheetah originally occurred widely in the Southern Alborz region, including in and around the present extent of Tehran. Nevertheless, recent surveys yielded no record of the cheetah presence in Jajroud PA, adjacent to Tehran (Eslami and Mahdavi 2007).

Today, the closest known cheetah population to Tehran is in Kavir NP, approximately $75 \mathrm{~km}$ to the east. Asadi (1997) estimated a population of 10-15 individuals although three camera trapping surveys between 2003 and 2010 of >5300 trap nights (Supplemental Material Table 1) recorded only two individuals. One of those, an adult male first 
Table 2 Details of cheetah mortalities in Iran between 2001 and 2012

\begin{tabular}{|c|c|c|c|c|c|}
\hline Number & Location & Age & Sex & Date of death & Cause of death \\
\hline 1 & Naybandan & Adult & Unknown & 2001 & Poacher; trapped \\
\hline 2 & $\begin{array}{l}\text { Kamki } \\
\text { Bahabad }\end{array}$ & Adult & Unknown & August 2002 & Suspected natural causes \\
\hline 3 & Bafq & Cub & Unknown & June 2003 & Killed by herder \\
\hline 4 & Bafq & Cub & Unknown & June 2003 & Killed by herder \\
\hline 5 & Bafq & Cub & Unknown & June 2003 & Killed by herder \\
\hline 6 & Bafq & Adult & Unknown & 2003 & $\begin{array}{l}\text { Unknown; found dead near } \\
\text { railroad }\end{array}$ \\
\hline 7 & Bafq & Adult & Unknown & 2003 & $\begin{array}{l}\text { Unknown; found dead near } \\
\text { railroad }\end{array}$ \\
\hline 8 & Dareh Anjir & Adult & Male (?) & Summer 2003 & Suspected natural causes \\
\hline 9 & Kavir & Adult & Unknown & 2004 & Suspected natural causes \\
\hline 10 & Kalmand & Adult & Female & January 2005 & Road collision \\
\hline 11 & Dareh Anjir & Unknown & Unknown & 2008 & Poacher \\
\hline 12 & Bafq & Adult & Female & $\begin{array}{l}\text { December } \\
2005\end{array}$ & Road collision \\
\hline 13 & Kalmand & Adult & Male & April 2006 & Road collision \\
\hline 14 & Kavir & Adult & Unknown & 2006 & Suspected natural causes \\
\hline 15 & Kalmand & Adolescent & Male & March 2007 & Road collision \\
\hline 16 & Bafq & Adult & Male & Summer 2007 & Leopard \\
\hline 17 & Kalmand & Adult & Female & April 2008 & Road collision \\
\hline 18 & Kalmand & Adult & Female & $\begin{array}{l}\text { November } \\
2008\end{array}$ & Road collision \\
\hline 19 & Darband & Adult & Male & $\begin{array}{l}\text { December } \\
2008\end{array}$ & Road collision \\
\hline 20 & Darband & Adult & Male & March 2009 & Poached; poisoned by miners \\
\hline 21 & Darband & Adult & Male & March 2009 & Poached; poisoned by miners \\
\hline 22 & Touran & Adult & Male & August 2009 & Suspected natural causes \\
\hline 23 & Touran & Adult & Female & $\begin{array}{l}\text { September } \\
2009\end{array}$ & Trapped by a poacher \\
\hline 24 & Touran & Adult & Female & July 2010 & Road collision \\
\hline 25 & Touran & Cub & Male & July 2010 & Road collision \\
\hline 26 & Touran & Cub & Female & July 2010 & Road collision \\
\hline 27 & Kalmand & Adult & Unknown & $\begin{array}{l}\text { December } \\
2010\end{array}$ & Probably road collision \\
\hline 28 & Naybandan & Adult & Male & March 2011 & Suspected natural causes \\
\hline 29 & Chah Shirin & Adolescent & Female & 2011 & Killed by herder \\
\hline 30 & Dareh Anjir & Adult & Male & Spring 2012 & Road collision \\
\hline 31 & Boshrouyeh & Adult & Unknown & Fall 2010 & Killed by herder \\
\hline 32 & Touran & Adult & Female & Fall 2012 & Killed by herder \\
\hline 33 & Touran & Adolescent & Male & $\begin{array}{l}\text { Winter } \\
2012 / 13\end{array}$ & Killed by herder \\
\hline 34 & Ardestan & Unknown & Unknown & & Killed by herder \\
\hline 35 & Ardestan & Unknown & Unknown & & Killed by herder \\
\hline 36 & Ardestan & Unknown & Unknown & & Killed by herder \\
\hline
\end{tabular}


Table 2 continued

\begin{tabular}{llllll}
\hline Number & Location & Age & Sex & Date of death & Cause of death \\
\hline 37 & Ardestan & Unknown & Unknown & & Killed by herder \\
38 & Darband & Adult & Female & $2011-2012$ & Killed by herder \\
39 & Darband & Cub & Unknown & $2011-2012$ & Killed by herder \\
40 & Darband & Cub & Unknown & $2011-2012$ & Killed by herder \\
41 & Darband & Cub & Unknown & $2011-2012$ & Killed by herder \\
42 & Khosh Yeilaq & Cub & Unknown 2012 & Killed by herder \\
\hline
\end{tabular}

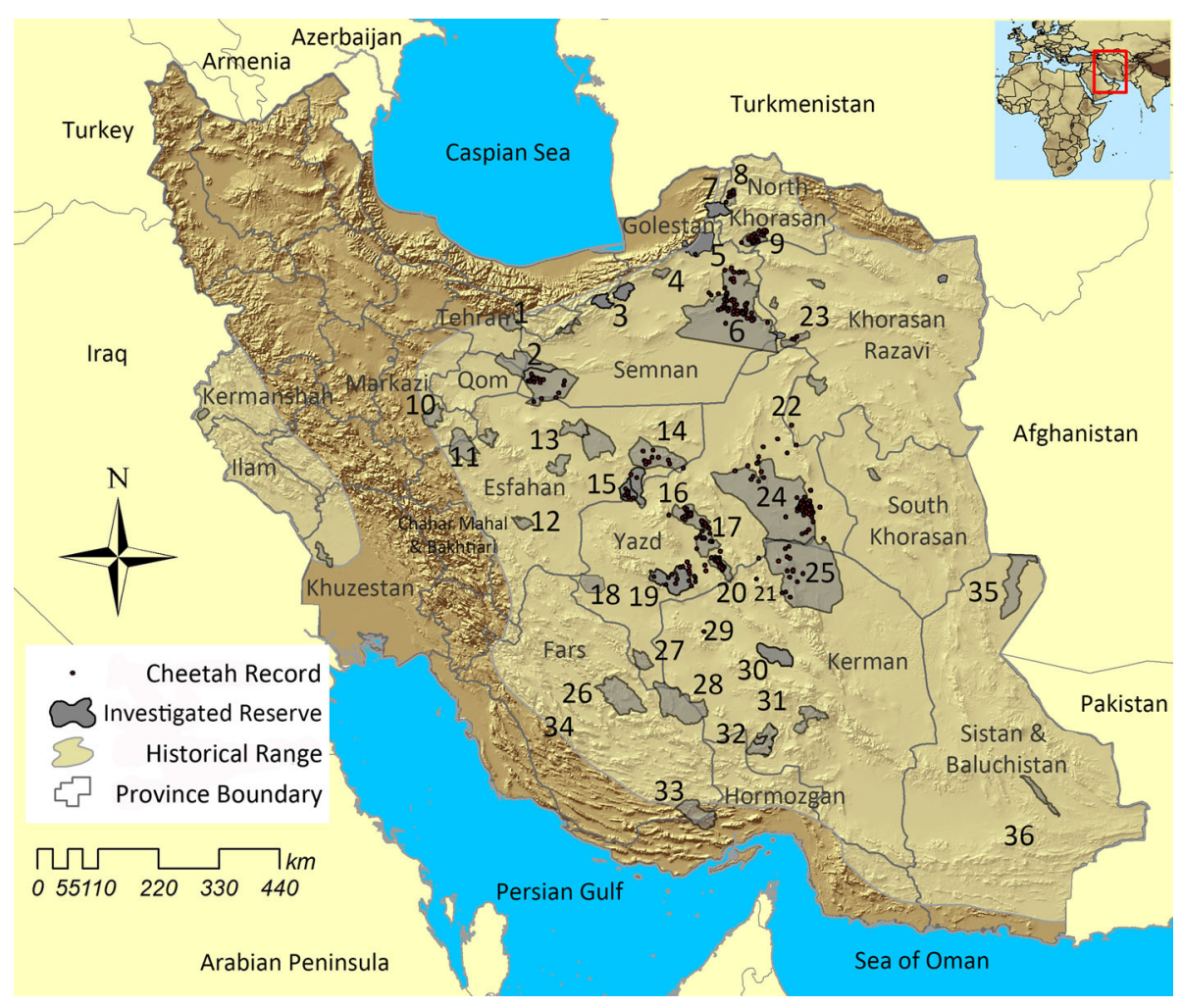

Fig. 1 Historical and present range of the Asiatic cheetah in Iran. Each province name is labelled on the map while numbers denote areas mentioned in the text. 1 Jajroud, 2 Kavir, 3 Parvar, 4 Sefidkouh Arask, 5 Khosh Yeilagh, 6 Touran, 7 Golestan, 8 Takhti Iran, 9 Miandasht, 10 Haftad Gholleh, 11 Mouteh, 12 Kolah Ghazi, 13 Ardestan, 14 Abbas Abad, 15 Siahkouh, 16 Dareh Anjir, 17 Ariz, 18 Abarkouh, 19 Kalmand, 20 Bafq, 21 Kamki Bahabad, 22 Boshrouyeh, 23 Dorouneh, 24 Naybandan, 25 Darband, 26 Bakhtegan, 27 Burouyeh, 28 Bahram-e-Gour, 29 Rafsanjan, 30 Bidouyeh, 31 Ebrahim Abad, 32 Khabr and Rouchoun, 33 Hormod, 34 Firouz Abad, 35 Hamoun, 36 Bampour

photographed in 2009 has been repeatedly photographed until summer 2014, probably the only cheetah in Kavir NP (Ghadirian et al. 2010). The last sighting of the cheetah with cubs dates to June 2007. 
During the late 1970s/early 1980s, an adult cheetah was kept by Iran DoE apparently captured near Damqan (Etemad 1985). The exact location of the cheetah's capture is not reported but is likely to be from Sefidkouh Arask (N35.977304\%/E53.951118 ; Asadi 1997). During the 1980s and 1990s, cheetahs were sighted there at least 35 times, including observation of a group of five cheetahs which were filmed by a local film crew (A. Saffari pers. comm.). No unequivocal evidence of cheetah is known from Sefidkouh Arask since 1997 when a dead male cheetah, probably shot, was found there. A stuffed cheetah in the Darabad Museum of Wildlife, Tehran is labeled as 'Damqan, 1969'.

Cheetahs were regularly reported around the city of Semnan until 2000, particularly from two reserves, Chah Shirin NHA (N34.727755\%/E54.059714 $)$ and Parvar PA $\left(\mathrm{N} 35.778935^{\circ} / \mathrm{E} 53.424676^{\circ}\right)$. In 2007 , a single cheetah was reported just within the city of Semnan $\left(\mathrm{N} 35.580141^{\circ} / \mathrm{E} 53.404238^{\circ}\right)$ although there is no physical evidence and the animal disappeared. There are recent reports of the species from Chah Shirin NHA, including a female cheetah reportedly killed by herders in 2011, that require surveys to validate.

Touran BR, in eastern Semnan Province, has been continually occupied by cheetahs until the present day (Etemad 1985; Asadi 1997; Farhadinia 2004; Ziaie 2008). Between 1990 and 2000, the cheetah was sighted there around 20 times, while over 150 observations have been recorded since 2000, the difference largely due to increased survey effort. In 2009, 39 cheetahs were seen on 16 occasions in Touran BR, almost twice the total number of sightings elsewhere in Iran. At least three cheetahs have been live captured and removed from Touran BR since 1984. Following negotiations between Iran and India to exchange Asiatic cheetah and Asiatic lion, a 7 month old male cheetah was captured in November 1984 and sent to Tehran. However, the exchange plan failed and the animal died in captivity. More recently, two cheetah cubs were captured illegally by local people in Touran BR, a 7 month old male ('Koushki') recovered in January 2008 (Jowkar et al. 2008) and a five month old female ('Delbar') recovered in April 2011. Both individuals are presently in captivity in Tehran to establish a captive breeding program.

Khosh Yeilagh WR $\left(\mathrm{N} 36.571509^{\circ} / 55.341439^{\circ}\right)$ was formerly famous for its uncommonly visible cheetahs which could be observed hunting urial wild sheep (Ovis orientalis) in hilly terrain (Firouz 1974; Goodwin and Holloway 1974; Dareshuri and Harrington 1976). During the 1970s-1980s, the population was crudely estimated at 20-30 (Dareshuri 1978; Joslin 1984), while inclusion of cubs in the guessed population number has not been noted by the authors. In 1970, a young female was found injured in Khosh Yeilagh and was sent to Tehran Zoo. The area experienced severe deterioration in the early 1980s with few subsequent sightings and the last cheetah was reported in 1983 (Aminian 1998). In May 2011, a pair of cheetahs was seen in Khosh Yeilagh, one of which was photographed.

\section{Kerman and Sistan-Baluchistan Provinces}

Except for one record of a male cheetah skin from Damin (N27.433333\%/E60.783345 $\left.{ }^{\circ}\right)$ in 1963 (Lay 1967; now stored in the Field Museum of Natural History, Chicago), the first official report of cheetahs in Kerman Province dates back to 1956 when one of us (HSh) saw two cheetahs killed in vicinity of city of Kerman. Later in 1970, a captured cheetah was sent to Tehran (Harrington 1971). Hasheminezhad (1996) provided five reports of cheetahs in around Khabr and Rouchoun NP and WR (N28.730532\%/E56.377323 ${ }^{\circ}$ ) between 1981 and 1988. There are sporadic, anecdotal reports from these provinces in recent years (Jahandari and Ameri pers. comm.) although unequivocal reports are restricted to Darband WR (N31.436527\%/E57.118438 $)$ and Rafsanjan (30.523611/55.348333) in far northern Kerman Province on the border with Yazd Province. Darband WR is located 
south of Naybandan WR, with which it is thought to comprise a contiguous cheetah population (Supplemental Material Table 2). The only recent records from Darband are of two male cheetahs poisoned by local miners and a male killed by a vehicle, all in 2008. Additionally there are plausible recent reports from Rafsanjan County (one report in 2007) and Bidouyeh PA (N30.524195/E57.215374 ${ }^{\circ}$ ). Ten credible sightings of cheetahs from Bidouyeh PA are known until the early 1990s (A. Beygmoradi pers. comm.), but no evidence was obtained during a recent effort made by Allahgholi et al. (2007).

In southeastern Iran, there is no recent evidence of cheetah presence despite its apparent former occurrence (Lay 1967; Firouz 1971). There is a single skin labeled as "Sistan" in a local museum in western Iran (E. M. Moqanaki pers. comm.). Firouz (1971) noted the presence of the cheetahs around Hamoun Lake (N30.852463\%/E61.610946 ${ }^{\circ}$ near the Afghanistan border. Just across the border, cheetah was known in the Helmand Basin (N32.298193\%/E62.248415 ${ }^{\circ}$ ) in Afghanistan (Hassinger 1973). Roberts (1997) presented sporadic reports on the cheetah's presence in western Pakistan before its extinction; he assumed Pakistan individuals were largely vagrants from extreme southwest Baluchistan, Iran where cheetahs persisted. A specimen was obtained from Bampour (N27.166983\% E60.512851 ${ }^{\circ}$ ) in Iran's Sistan-Baluchistan Province in 1960s (Lay 1967). The most recent effort to search for the cheetahs in the Iran-Pakistan borderlands produced no evidence (Husain 2001).

\section{Esfahan, Qom and Markazi Provinces}

The cheetah formerly occurred in western/central Esfahan Province in Kolah Ghazi NP $\left(\mathrm{N} 32.375616^{\circ} / \mathrm{E} 51.911782^{\circ}\right)$ and Mouteh WR (N33.687054\%/E50.784214 $\left.{ }^{\circ}\right)$. Kolah Ghazi NP was regarded as an important site for cheetahs until the late 1970s (Firouz 1971, 1974) with evidence of a declining population between 1978 and 1984 when records become very sporadic. A cheetah with a single cub was observed in Mouteh WR in 1974 (Dareshuri 1978), with no further observations, except for a few unconfirmed reports in the late 1990s (A. Moghaddam pers. comm.). Both areas have maintained large populations of the goitered gazelle (Gazella subgutturosa), but the cheetahs have vanished (Ziaie 2008).

Today, the cheetah is restricted to eastern Esfahan Province, particularly Abbas Abad WR (Farhadinia et al. 2008a), confirmed by a camera trap image in autumn 2010. Cubs were also observed in two recent cases (litters of 1 and 3 ). There are two records of cheetahs killed by poachers from Ardestan (N33.483504\%/E52.460902 $)$, most recently during the 1990s (H. Akbari pers. comm.).

Bordering Esfahan Province, there are some reports of the species from Markazi Province (Karami 1992) which lack certainty. There is a skull dating prior to 1980 in the Iranian Museum of Natural History, labeled as "CEN" which is probably from this province. Asadi (1997) noted a credible report from the Haftad Gholleh PA (N34.029412\% E50.161516 ${ }^{\circ}$ although there is no further detail. There are occasional, recent rumors of the species' presence in Markazi (N34.049318\%/E50.407608 ; A. Ansari pers. comm.) but there are no empirical data.

\section{Hormozgan and Fars Provinces}

Located north of the Hormoz Strait, Hormozgan Province has never been properly surveyed for the cheetah. Khalili (1984) and Asadi (1997) believed the species occurred in Hormozgan; however, except a cheetah which was kept by Iran Department of Environment in Tehran reportedly from the region in 1973, there are no certain records. It is 
possible the cheetah still occurs in far northern and eastern Hormozgan within historic range although we believe this is unlikely.

There is no recent evidence of the cheetah in Fars Province. A survey of the Abadeh region in 1999 produced no evidence of cheetahs (Farhadinia, unpubl data). Hormod $\left(\mathrm{N} 27.439993^{\circ} / \mathrm{E} 55.400725^{\circ}\right)$ and Bakhtegan $\left(\mathrm{N} 29.561652^{\circ} / \mathrm{E} 53.870224^{\circ}\right)$ have been referred to as a cheetah area in the 1970s (Firouz 1971), but there are no data. There are two images of shot cheetahs from the 1960s and early 1970s from Firouzabad $\left(\mathrm{N} 28.954701^{\circ} / \mathrm{E} 52.591543^{\circ}\right.$ ), southern Fars Province (A. Zolfaghari pers. comm.). The cheetah in Fars was most recently recorded from the Bahram-e-Gour PA (N29.178614\% E54.536526 ${ }^{\circ}$ ) with experienced occasional sightings until the mid-1970s (Dareshuri 1978; Khalili 1984; Etemad 1985; Hajji 1986; Karami 1992; Asadi 1997; Jowkar 1999). Dareshuri (1978) reported that during a period of five years in mid-1970s, only two cheetahs were sighted in Bahram-e-Gour PA. In the 1980s, only one reliable report exists from the area, made by Dareshuri (personal communication) of a solitary individual, with an unlikely population estimate given of 10 to 20 cheetahs (Dareshuri 1987; Khalili 1984). Survey efforts by Ghoddousi et al. (2007) failed to find evidence of the species in the area.

\section{Khorasan (North, South and Razavi Khorasan Provinces) and Golestan}

Dorouneh PA (N35.184692\%/E57.011001 ${ }^{\circ}$ ) in Razavi Khorasan Province was formerly well-known for its biodiversity, including the cheetah. In August 1980, two cubs of each sex were confiscated from a local herder in Sabzevar market who apparently captured them close to Dorouneh PA, and were moved to Mashad Zoo where the female lived to August 1984 and the male lived until the end of 1993 (Karami 1992). Except for a single cheetah killed (presumably by local people) in September 1992, a trickle of reports from Razavi Khorasan are largely equivocal (Asadi 1997; A. Zahiri pers. comm.) until June 2012 when an adult female cheetah was photographed after regular attacks on livestock in Dorouneh PA.

In North Khorasan Province, the cheetah definitively occurs only in Miandasht WR and Takhti Iran NHA. This is the northernmost occurrence of the species in Iran, and the plausible source of the most recent records in neighbouring Turkmenistan (Mallon 2007). Miandasht WR has a resident, breeding cheetah population. Between 2002 and 2012, 115 cheetahs were sighted on 63 occasions, with at least four different litters known since 2002. In contrast, presence in Takhti Iran NHA has been confirmed based only on recent cheetah tracks and over 20 sightings obtained during interview surveys with local people in the area; there is no evidence of breeding (Farhadinia et al. 2008b). Close to Takhti Iran NHA, the cheetah formerly occurred in eastern Golestan NP, Golestan Province. Kiabi et al. (1993) reported at least three individuals in the park up until 1979. Furthermore, there is a cheetah skin in the DoE museum, probably from eastern Golestan Province (M. Shakiba pers. comm).

In neighbouring Turkmenistan, it is believed that cheetahs probably disappeared by the mid-1980s, though a few individuals may have persisted longer (Mallon 2007; Kaczensky and Linnell 2015). It is believed that cheetahs formerly moved from northeast Iran across the border into southern Turkmenistan, but the construction of a border fence has made cross-border movement unlikely (Mallon 2007). Southern Turkmenistan retains suitable habitat and prey to host a small cheetah population if re-colonisation or reintroduction was possible (Breitenmoser 2002; Kaczensky and Linnell 2015).

Naybandan WR, in South Khorasan Province, was assumed to hold one of the largest populations of the cheetahs in Iran (Jourabchian 1999). Accordingly, it was a key focus for 
camera-trapping efforts from 2001 forwards, with a search effort of over 11,000 trap nights in seven separate surveys. A total of 74 images of cheetahs of at least 15 different individuals have been caught in Naybandan WR on 55 independent occasions (M. Eslami pers. comm.). The first cheetah photo-trapped in this area is also the longest lived wild Asiatic cheetah with an estimated minimum age of 14, based on images available between 2001 and 2011.

There are sporadic reports of the cheetahs from the northern city of Tabas, including reliable reports of local people killing cheetahs in Halvan (Karami 1992; B. Najafi pers. comm.). In 2011, an image was found showing a herder with his dog on a dead adult cheetah body killed near Boshrouyeh (N33.791068\%/E57.221865', M. Eslami pers. comm.), some $250 \mathrm{~km}$ north of Naybandan WR.

The cheetahs were known to exist in parts of western Afghanistan (Habibi 2003), notably near Herat (Aitchison 1889). It is plausible that very few individuals still occur near the border with Iran (Manati and Nogge 2008) although there is no recent evidence to support any borderland population between Iran and Afghanistan.

\section{Yazd Province}

Located in the centre of Iran and of cheetah distribution, Yazd Province has long been considered as a key region for the species. The two most important reserves are the Dareh Anjir WR and Bafq PA with five and two different families respectively confirmed since 2001. Cheetahs are known to also occur adjacent to Bafq PA, in Kalmand PA $\left(\mathrm{N} 31.494622^{\circ} / \mathrm{E} 54.485200^{\circ}\right)$ where Yazd Province's first official record originates, a dead cheetah found in the late 1970s (A. Mortazavi pers. comm.). Since then, at least six cheetahs have been killed between 2004 and 2009, most of them from vehicle collisions on a major highway which runs through Kalmand PA.

Elsewhere in Yazd, Kamki Bahabad NHA (N31.983371\%/E56.185371 ${ }^{\circ}$ ) is also known to be cheetah area, based on a dead cheetah found in 2000 and sightings by game guards and locals, including a group of five cheetahs observed in spring 2009 (A. Ghanbarizadeh pers.com.). Siahkouh NP (N32.735074\%/E54.786981 $\left.{ }^{\circ}\right)$ is the most recent reserve in the province to record cheetahs, confirmed by images of mother and three cubs in summer 2010. In Burouyeh WR (N30.487747\%/E53.616296 ${ }^{\circ}$ ) and Abarkouh (N31.224188\% E53.671930 ${ }^{\circ}$, there are rumors of the species occurrence until the end of 1970s (M. Aziz and M. Teymuri pers. comm.) with no recent evidence.

\section{Zagros Region}

There are no recent records of the cheetah from the Zagros. The cheetah is mostly known from the extreme eastern Zagros range where mountainous terrain gives way to the desert habitat of Yazd and Kerman, but there are sporadic historical reports of the species from the more hilly and plain areas of the central Zagros in Kermanshah (Ziaie 2008; M. Atarodi pers. comm.) and Chahar Mahal and Bakhtiari Provinces (Farhang 1997). In early 1970, a cheetah was shot in Naft Shahr, near Iraq border and there is a photograph from the 1960s of the skin of a female cheetah killed near Farrokhshahr (N32.291169 /E51.035337 $)$ in Chahar Mahal and Bakhtiari Province (Farhang 1997). 


\section{Population status}

We compiled information 12 independent population estimates conducted since early 1970s based on expert opinions (Table 3) which showed two different eras. Up to the end of the 1970s, a few hundred cheetahs inhabited the country, in contrast to a few dozen for subsequent decades.

\section{Discussion}

\section{Status of the Asiatic cheetah in Iran}

Prior to World War II, the cheetah was believed to occur in almost all of the steppes and desert areas of the eastern and some western regions of Iran near the Iraqi border (Harrington 1971), which was equal to two-thirds of the country area (Jourabchian and Farhadinia 2008). In 1959, the Iranian Game Council, the statutory wildlife authority at the time, declared the cheetah protected by law and there followed a period of dedicated conservation effort (Firouz 1974). In the 1970s, the cheetah's range was regarded as essentially intact drylands of eastern half of Iran (Firouz 1971, 1974). Thus, parallel to the disappearance of the last Asiatic cheetahs outside Iran by the end of 1970s (Nowell and Jackson 1996; Roberts 1997; Habibi 2003; Mallon 2007), the species was still widespread in Iran, albeit in low densities dispersed over a vast area. They were presumed to have an increasing population trend by the end of 1970s, due to sound conservation efforts (Dareshuri and Harrington 1976; Mowlavi 1985).

The civil revolution in 1979 and subsequent eight year war with Iraq effectively ceased organized wildlife conservation activities in Iran. Except for some limited surveys in the late 1990s (e.g., Karami 1992; Asadi 1997; Dareshuri 1997; Jowkar 1999; Jourabchian 1999), the species did not attract dedicated research and protection effort until 2001. To our knowledge, the cheetah was photographed only three times in Iran during the 1980s and 1990s, and it was assumed to have almost disappeared from the entire country (Jackson

Table 3 Cheetah population estimates in Iran

\begin{tabular}{ll}
\hline Estimation based on expert opinion & Reference \\
\hline 400 & Harrington (1971) \\
$200-300$ & Firouz cited in Goodwin and Holloway (1974) \\
100 & Joslin (1984) \\
$50-100$ & Asadi (1997) \\
$>40$ & Jourabchian (1999) \\
$>60$ & Schaller and O'Brien (2001) \\
$50-60$ & Farhadinia (2004) \\
$70-120$ & Jourabchian and Farhadinia (2008) \\
$60-100$ & Jowkar et al. (2008) \\
$70-100$ & Ziaie (2008) \\
$<70$ & Farhadinia et al. (2014) \\
$<50$ & Durant et al. (2016) \\
\hline
\end{tabular}

\footnotetext{
a The figure reported for mid-1970s
} 
1998). By mid 1990s, the Asiatic cheetah was thought to reside in only a few, mostly disjunct areas cumulatively comprising almost 38,000 $\mathrm{km}^{2}$ (Asadi 1997; Jourabchian and Farhadinia 2008; Ziaie 2008).

The global distribution of the Asiatic cheetah is today restricted to Iran's central plateau where it inhabits approximately $242,500 \mathrm{~km}^{2}$. We consider this as a best estimate, as it contains large areas of low quality habitat which are of very limited ecological value to large mammals, and are largely devoid of records of cheetahs. The known range of the Asiatic cheetah expanded considerably over the 2000s, mainly due to increased survey effort rather than actual range recovery or expansion.

It appears the current range of the cheetah in Iran comprises three main population nuclei (Moqanaki and Cushman 2016; Farhadinia et al. 2016b), namely Southern Landscape (including Bafq PA, Dareh Anjir WR, Siahkouh NP and PA, Kalmand PA, Abbas Abad WR, Ariz NHA, Kamki Bahabad NHA, Rafsanjan County, Boshrouyeh County, and the complex of Naybandan WR and Darband WR), Northern Landscape (Touran BR and five smaller areas around, namely Dorouneh PA, Miandasht WR, Khosh Yeilagh WR, Chah Shirin NHA and Takhti Iran NHA) and Kavir. Located at the north-west limit of the species' current range, the latter is distant from the two main population nuclei with very few cheetahs and irregular records of breeding. It is urgent to establish whether movement corridors exist between Kavir NP and the rest of cheetah distribution in the country (Moqanaki and Cushman 2016).

While the introduction of camera trapping to Iran in 2001 has considerably improved knowledge of the cheetah's distribution, robust population estimates remain elusive. Asiatic cheetahs occur in extremely low densities, move vast distances and inhabit open, arid habitat where it is challenging to locate productive sites for camera-traps. Conventional mark-recapture models are extremely difficult to apply due to the resulting very low detection probability, particularly for females.

\section{Direct threats to cheetahs}

Based on available records of cheetah casualties $(n=42)$ between 2001 and 2012, anthropogenic factors accounted for the largest proportion of known mortalities. Local herders are currently the single most important cause of human-induced mortalities, typically in association with herd dogs. Herders in Iran make little effort to control dogs and they are known to freely harass wildlife, including cheetahs (Asadi 1997; Ziaie 2008). While evidence of cheetah depredation on domestic animals is uncommon in Iran (Karami 1992; Farhadinia et al. 2012, 2016b), most of the herder-mediated casualties are considered to be due to the cheetah being perceived as a threat to livestock.

Encounters between herders and cheetahs are presumably rare given the latter's extremely low densities, and avoidance of people. There are, for example, no known records of cheetahs harassing livestock in villages or corrals. Additionally, the Iranian authorities impose very strong deterrents for the killing of cheetahs, including jail time and high fines (currently 1billion IRR equal to US\$ 28,570; Farhadinia et al. 2016b) which might be expected to suppress illegal behavior.

Almost equally important as a source of mortality is Iran's extensive and rapidly growing network of roads. It is especially prevalent in Touran BR and Kalmand PA which accounted for $75 \%$ of the country's cheetah road deaths between 2001 and 2012. Major highways do not occur in or near all other cheetah reserves which have local roads with less traffic, somewhat mitigating the risk of road collisions for cheetahs (Moqanaki and Cushman 2016). 
Clearly, our mortality figures represent a minimum estimate and some mortality sources are likely under-represented in our figures. Anthropogenic killing of cheetahs by herders occurs illicitly, usually in remote sites and attempts to conceal the event are often made i.e., cheetah carcasses were removed or burned in $56.3 \%$ of the herder-caused casualties. Accordingly, this threat is likely to be underestimated in our mortality.

Intentional shooting or poisoning of cheetahs seem uncommon in Iran, possibly because encountering cheetahs in the wild is a rare, accidental event. Most poaching cases in our database result from trapping and poisoning, in which cheetah was probably not the intended target. Furthermore, there is no evidence of trade in cheetahs from Iran to Persian Gulf's Arab states in contrast to well-known export routes from north-east Africa (Nowell 2014). However, there have been occasional rumors of cheetah shooting in remote areas, which have never been confirmed, possibly because of the incurred very high penalty (currently 1billion IRR equal to US\$28,570). Nevertheless, in the context of a very small and declining population size, any targeted poaching by people is extremely concerning.

In contrast, we believe we have accounted for most road fatalities which are difficult to conceal, although it is impossible to rule out occasional cases of collection of road-killed cheetahs by the public (which is illegal in Iran). In contrast, many cheetahs dying of natural causes in the field are never found and do not attract the same level of attention as anthropogenic deaths. Although this biases our data towards anthropogenic mortality factors, it is nonetheless evident that frequent human-mediated deaths comprise a very significant cause for concern for the few remaining members of this population.

\section{Conservation implications}

Cheetah in Iran are presently restricted to extremely arid regions where they show nomadic ranging behavior, covering several reserves (Farhadinia et al. 2016a). Therefore, efforts to protect the cheetahs and their prey must be coordinated at both national as well as defined landscape levels, rather than within reserves, because they are likely to share the same individuals. Such an approach needs to account for the importance of both core areas and movement corridors.

In the immediate term, it is essential that the main sources of anthropogenic mortality are reduced. Firstly, we believe that dogs should be reduced significantly from the cheetah protected areas through a participatory process in which herders' concerns are addressed. Requiring mandatory attendance at education workshops intended to address herders' behavior of harassing the cheetahs (and other wildlife) could be linked to the permissions required by the Iranian government for grazing in protected areas.

In concert with this process, incentives linked to conservation outcomes must be explored with herding communities. A compensation program for depredation on livestock by carnivores is run by the Iranian DoE/CACP. As a supplementary solution, it would also be interesting to assess the viability of rewarding herders for cheetah sightings and information. Performance-payment type programs, such as those run for wolverines Gulo gulo in Sweden (Persson et al. 2015) as well as raising livestock productivity through gratis livestock vaccinations may improve co-existence between cheetahs and communities. An effective vaccination program would also help address disease transmission between livestock and wild ungulates which has previously resulted in mortalities of cheetah prey in Iranian protected areas (Schaller and O'Brien 2001).

To date, efforts to reduce road collisions of cheetahs have focused on signage, advising drivers to reduce speed and stay alert for cheetahs crossing. However, their effectiveness has not been assessed but it is likely that larger-scale solutions are required (Mohammadi 
and Kaboli 2016). Wildlife crossings, overpasses and underpasses have reduced mortality and increased connectivity for large carnivores elsewhere (see Grilo et al. 2015 for a review). Their effectiveness relies, inter alia, on targeting collision hotspots for which some data already exist. Most documented cheetah road deaths have occurred on a small number of known stretches of highway passing through hilly terrain far from flat, open areas (Mohammadi and Kaboli 2016).

While our review focuses on the direct threats to cheetahs, serious indirect threats also affect the species, primarily through impacts on habitat suitability and prey abundance. The key indirect factor currently affecting cheetah numbers in Iran is thought to be the disappearance of prey (Hunter et al. 2007; Breitenmoser et al. 2009; Farhadinia et al. 2012) due to human hunting, and the loss of habitat due to the combined effects of livestock overgrazing and drought (Karami 1992; Asadi 1997; Ziaie 2008). Thus, controlling anthropogenic threats to wild ungulates is crucial, particularly ongoing illegal poaching which is still a serious threat (Breitenmoser et al. 2009). Moreover, overgrazing by livestock must be addressed more effectively to revise and control existing grazing permissions which are based on historical right of access rather than the actual carrying capacity of dryland pasture. Related to this, it would be extremely useful to review the present regime of artificial water sources inside cheetah distribution and how they are used by the cheetahs, prey species and livestock.

Finally, within cheetah range, the most rapid and extensive development is driven by the mining sector's exploration and exploitation activities. Compounding the immediate loss of important habitat, mining requires the construction of new roads and railways increasing the vulnerability of cheetahs to accidents and facilitating access for poachers.

Our research highlights the importance of a centralized monitoring program for cheetahs in Iran. The present paper is the first to compile data derived from different methods, i.e., camera trapping, opportunistic photos, and citizen science data, and it provides the basis for a more coordinated monitoring program. Monitoring, particularly by means of camera traps has been extremely useful for identifying important sites for cheetahs and has helped direct conservation efforts at those sites. However, these data are very limited in providing cheetah population estimates and detecting changes in population status (Breitenmoser et al. 2009). To overcome these challenges, we recommend a coordinated, longterm monitoring program for Iran's principal cheetah areas. Such a program should establish long-term fixed monitoring stations (i.e., camera sites) across the most important cheetah sites, all of which would be surveyed during the same survey window each year, thus providing a consistent minimum annual count of cheetahs across the majority of known cheetah range at the same time. Comparisons over subsequent years are expected to provide information of trends in the population, and supply other useful information including demographic parameters and population dynamics over time (Karanth et al. 2006).

In contrast to approximately $11 \%$ of former range hosting the African cheetahs (Durant et al. 2015), the current area for the Asiatic cheetahs still encompasses almost $23.2 \%$ of their historic range. Accordingly, while we acknowledge that the extant Asiatic cheetah population is extremely small and fragile, availability of vast expanses of habitat is a major hope for conservation of the Asiatic cheetah. Iran should be congratulated in its efforts to conserve the last Asiatic cheetahs, but the future of this unique population is by no means assured. Undoubtedly, the Asiatic cheetah will remain entirely dependent on effective conservation actions in which increased coordination at the national level and greater investment from the international conservation community will be essential. 
Acknowledgements We thank the GEF/UNDP Iran for provision of necessary funds for the CACP to implement conservation measures since 2001. DoE provincial offices within the range of the cheetahs in Iran collaborated during data gathering. Many Iranian experts, hunters, collection owners, and game guards kindly provided valuable information about their Asiatic cheetah sightings and specimens. Three anonymous reviewers gave helpful comments on an earlier version of this manuscript.

Open Access This article is distributed under the terms of the Creative Commons Attribution 4.0 International License (http://creativecommons.org/licenses/by/4.0/), which permits unrestricted use, distribution, and reproduction in any medium, provided you give appropriate credit to the original author(s) and the source, provide a link to the Creative Commons license, and indicate if changes were made.

\section{References}

Aitchison JET (1889) The zoology of the Afghan delimitation commission. Tran Linn Soc Lond Ser Zool 5(3):53-142

Allahgholi MA, Yusefi H, Khalatbari L, Mobargha M (2007) Status of Asiatic cheetah in Bidouyeh Protected Area. Conservation of Asiatic Cheetah Project, final report, Tehran, Iran (in Persian)

Aminian GH (1998) Natural environment in Khosh Yeilagh Wildlife Refuge. BSc thesis, University of Environment, Tehran, Iran (in Persian)

Asadi H (1997) The environmental limitations and future of the Asiatic cheetah in Iran. Project progress report, IUCN/SSC Cat SG, Tehran

Breitenmoser U (2002) Feasibility study on cheetah re-introduction in Turkmenistan. Cat News, pp 13-15

Breitenmoser U, Alizadeh A, Breitenmoser-Würsten C (2009) Conservation of the Asiatic cheetah, its natural habitat and associated biota in the I.R. of Iran

Caro T (1994) Cheetahs of the serengeti plains. University of Chicago Press, Chicago

Charruau P, Fernandes C, Orozco-Terwengel P, Peters J, Hunter L, Ziaie H, Jourabchian A, Jowkar H, Schaller G, Ostrowski S, Vercammen P, Grange T, Schlötterer C, Kotze A, Geigl E, Walzer C, Burger P (2011) Phylogeography, genetic structure and population divergence time of cheetahs in Africa and Asia: evidence of long-term geographic isolates. Mol Ecol 20:706-724

Dareshuri BF (1978) Threatened cats of Asia: Asiatic cheetah. Wildlife, September, pp 396-397

Dareshuri BF (1987) Cited in C. Groves. 1987. Report on visit to protected areas in Iran. United Nations Development Programme

Dareshuri BF (1997) Cited in Rezaei F. 2002. Cheetah in Iran. Donyayey Vahsh Q 1(3):14-18 (in Persian)

Dareshuri BF, Harrington FA (1976) A guide to the mammals of Iran. Department of the Environment, Tehran (in Persian)

Durant SM, Mitchell N, Ipavec A, Groom R (2015) Acinonyx jubatus. The IUCN red list of threatened species 2015: e.T219A50649567. doi:10.2305/IUCN.UK.2015-4.RLTS.T219A50649567.en. Accessed 12 April 2016

Durant SM, Mitchell N, Groom R, Pettorelli N, Ipavec A, Jacobson AJ, Woodroffe R, Bohm M, Hunter LT, Becker M, Broekhuis F et al (2016) Disappearing spots, the global decline of cheetah and what it means for conservation. In: Proceedings of the National Academy of Sciences of USA

Ellerman JR, Morrison-Scott TCS (1966) Cheetah. In: Checklist of Palaearctic and Indian Mammals 1758 to 1946, 2nd ed. Trustees of the British Museum of Natural History, London pp 320-321

Eslami M, Mahdavi AR (2007) A baseline survey on Khojir carnivores. Project final report, Tehran Provincial Office of Department of Environment (in Persian)

Etemad E (1985) Mammals of Iran. 2nd Volume. Iranian Department of the Environment (in Persian)

Farhadinia MS (2004) The last stronghold: cheetah in Iran. Cat News 40:11-14

Farhadinia MS, Akbari H, Beheshti M, Sadeghi A (2008a) Felids of Abbasabad Naein Reserve, Iran. Cat News 48:14-16

Farhadinia MS, Nezami B, Hosseini-Zavarei F (2008b) Status of the Asiatic cheetah in North Khorasan Province. Department of Environment (in Persian)

Farhadinia MS, Hosseini-Zavarei F, Nezami B, Harati H, Absalan H, Marker L, Fabiano F (2012) Feeding ecology of the Asiatic cheetah Acinonyx jubatus venaticus in low prey habitats in northeastern Iran: implications for effective conservation. J Arid Environ 87:206-211

Farhadinia MS, Akbari H, Mousavi SJ, Eslami M, Azizi M, Shokouhi J, Gholikhani N, Hosseini-Zavarei F (2013) Exceptionally long movements of Asiatic cheetah Acinonyx jubatus venaticus across multiple arid reserves in central Iran. Oryx 47(3):427-430 
Farhadinia MS, Eslami M, Hobeali, K, Hosseini-Zavarei F, Gholikhani N, Taktehrani A (2014) Status of Asiatic cheetah in Iran: a country-scale assessment. Project final report, Iranian Cheetah Society (ICS), Tehran, Iran, 26 pp

Farhadinia MS, Gholikhani N, Behnoud P, Hobeali K, Taktehrani A, Hosseini-Zavarei F, Eslami M, Hunter LTB (2016a) Wandering the barren deserts of Iran: illuminating high mobility of the Asiatic cheetah with sparse data. J Arid Environ 30(134):145-149

Farhadinia MS, Akbari H, Eslami M, Adibi MA (2016b) A review of ecology and conservation status of Asiatic cheetah in Iran. Cat News 10:18-26

Farhang M (1997) An encounter with the cheetah. Sherkar-o-Tabiat (Hunt Nat ) Mag 47:42-45

Firouz E (1971) Game management and protection in Iran. Iran Game Management Organization, Tehran (in Persian)

Firouz E (1974) Environment Iran. National Society of the Conservation of Natural Resources and Human Environment, Tehran

Ghadirian T, Eslami M, Hamidi AKh, Moqanaki EM (2010) Minimum population assessment of the Asiatic cheetah Acinonyx jubatus venaticus using camera photo-trapping in Kavir National Park, Iran. Final report to the Conservation of the Asiatic Cheetah Project (CACP), Tehran (in Persian)

Ghoddousi A, Habibi Moghaddam A, Ashayeri D, Fahimi H (2007) Status of Asiatic cheetah in Bahram-eGour Protected Area. Conservation of Asiatic Cheetah, Final report, Tehran, Iran (in Persian)

Goodwin H, Holloway C (1974) Red data book, vol 1. IUCN, Basel

Grilo C, Smith DJ, Klar N (2015) Carnivores: struggling for survival in roaded landscapes. Handbook of road ecology

Groves C (1987) Conservation in Iran, Report to United Nations Development Programme, Project Number IRA/87/014/A/01/12, 13 pp

Habibi K (2003) Mammals of Afghanistan. Zoo Outreach Organization, Coimbatore

Hajji A (1986) An introduction to the cheetahs of Iran. BSc thesis, Shahid Beheshti University, Tehran (in Persian)

Harrington FA (1971) Present status of the cheetah in Iran. Unpublished typescript report

Hasheminezhad H (1996) Endangered fauna of Kerman. Abi [Blue] Newsletter, Kerman Provincial Office of Department of Environment, vol 4, pp 13-15

Hassinger JDA (1973) Survey of the mammals of Afghanistan. Fieldiana Zool 60:159-161

Hunter L, Jowkar H, Ziaie H, Schaller G, Balme G, Walzer C, Ostrowski S, Zahler P, Robert-Charrue N, Kashiri K, Christie S (2007) Conserving the Asiatic cheetah in Iran: launching the first radio-telemetry study. Cat News 46:8-11

Husain T (2001) Survey for the Asiatic cheetah, Acinonyx jubatus, in Balochistan province. Pakistan Barbara Delano Foundation

IUCN (2001) IUCN Red List Categories. Version 3.1. Gland, Switzerland: International Union for the Conservation of Nature, Species Survival Commission

Jackson P (1998) Asiatic Cheetah in Iran. Cat News 28:2-3

Joslin P (1984) Cited in Divyabhanusinh. 1984. The origin, range and status of the Asiatic (or Indian) cheetah or hunting leopard (Acinonyx jubatus venaticus) — a tentative position paper. In: Jackson $\mathrm{P}$ (ed) The plight of the cats. Proceedings of the meeting and workshop of the IUCN/SSC Cat Specialist Group, Kanha National Park, Madhya Pradest, India, pp 183-195

Jourabchian AR (1999) Cheetah status in Khorasan Province. Khorasan Provincial Department of the Environment, Mashad (in Persian)

Jourabchian AR, Farhadinia MS (2008) Final report on Conservation of the Asiatic cheetah, its Natural Habitats and Associated Biota in Iran. Project Number IRA/00/G35 (GEF/UNDP/DoE), Tehran, Iran (in Persian with English summary)

Jowkar H (1999) The preliminary study on Asiatic cheetah and its status in Iran. BSc thesis, Islamic Azad University, Tehran, Iran (in Persian)

Jowkar H, Ostrowski S, Hunter L (2008) Asiatic cheetah cub recovered from a poacher in Iran. Cat News 48:13

Kaczensky P, Linnell JD (2015) Rapid assessment of the mammalian community in the Badhyz Ecosystem, Turkmenistan. NINA Report 1148

Karami M (1992) Cheetah distribution in Khorasan Province, Iran. Cat News 16:4

Karanth KU, Nichols JD (2002) Monitoring tigers and their prey: a manual for researchers, managers and conservationists in tropical Asia. Centre for Wildlife Studies, Bangalore

Karanth KU, Nichols JD, Kumar NS, Hines JE (2006) Assessing tiger population dynamics using photographic capture-recapture sampling. Ecology 87:2925-2937

Khalili SM (1984) State of the cheetah in Iran. Environ Q 28:2-11 (in Persian) 
Kiabi BH, Dareshuri BF, Madjounian H (1993) Golestan National Park. Iranian Department of the Environment, Tehran, $172 \mathrm{pp}$ (in Persian)

Lay DM (1967) A study of the mammals of Iran, Fieldiana Zoology, vol 54. Field Museum of Natural History, Chicago

Mallon DP (2007) Cheetahs in central Asia: a historical summary. Cat News 46:4-7

Manati AR, Nogge G (2008) Cheetahs in Afghanistan. Cat News 49:18

Marker LL, Dickman A (2003) Morphology, physical condition, and growth of the cheetah (Acinonyx jubatus jubatus). J Mammal 84(3):840-850

Mohammadi A, Kaboli M (2016) Evaluating wildlife-vehicle collision hotspots using kernel-based estimation: a focus on the endangered Asiatic cheetah in central Iran. Hum Wildl Interact 10(1):103

Moqanaki EM, Cushman SA (2016) All roads lead to Iran: predicting landscape connectivity of the last stronghold for the critically endangered Asiatic cheetah. Anim Conserv. doi:10.1111/acv.12281

Mowlavi M (1985) Cheetah in Iran. Cat News 2:7

Nowell K (2014) An assessment of the conservation impacts of legal and illegal trade in cheetahs Acinonyx jubatus. IUCN SSC Cat Specilaist Group report prepared for the CITES Secretariat, 65th meeting of the CITES Standing Committee, Geneva, 7-11 July. CITES SC65 Doc. 39

Nowell K, Jackson P (1996) Wild cats: status survey and conservation action plan. IUCN, Gland

Persson J, Rauset GR, Chapron G (2015) Paying for an endangered predator leads to population recovery. Conserv Lett 8(5):345-350

Pocock RI (1939) The fauna of British India, Mammalia, I. Primates and Carnivora, 2nd edn. Taylor and Francis, London

Roberts TJ (1997) The mammals of Pakistan. Oxford University Press, Karachi

Schaller GB, O'Brien T (2001) A preliminary survey of the Asiatic cheetah and its prey in the I. R. of Iran. Report to WCS, Iran DoE and UNDP-GEF

Ziaie H (2008) A field guide to mammals of Iran, 2nd edn. Wildlife Center Publication, Tehran (in Persian) 